\title{
Analysis of the Cavity Formation Mechanism of Wedge Cut Blasting in Hard Rock
}

\author{
Zhongkang Wang $\mathbb{D D}^{1,2}$ Xiaowei Gu ${ }^{\mathbb{D}},{ }^{1,2}$ Wenlong Zhang, ${ }^{3}$ Qiankun Xie, ${ }^{4}$ Xiaochuan Xu, ${ }^{2}$ \\ and Qing Wang ${ }^{2}$
}

${ }^{1}$ Key Laboratory of Ministry of Education on Safe Mining of Deep Metal Mines, Northeastern University, Shenyang 110819, China

${ }^{2}$ School of Resources and Civil Engineering, Northeastern University, Shenyang 110819, China

${ }^{3}$ Guangdong People Blasting Engineering Co. Ltd., Guangzhou 510000, China

${ }^{4}$ The First Engineering Co. Ltd. of CTCE Group, Hefei 230041, China

Correspondence should be addressed to Xiaowei Gu; guxiaowei@mail.neu.edu.cn

Received 18 December 2018; Revised 12 March 2019; Accepted 9 April 2019; Published 9 May 2019

Academic Editor: Fabio Minghini

Copyright (c) 2019 Zhongkang Wang et al. This is an open access article distributed under the Creative Commons Attribution License, which permits unrestricted use, distribution, and reproduction in any medium, provided the original work is properly cited.

\begin{abstract}
The basic process of cut blasting is to break rock, throw fragments, and form a cavity. Based on the characteristics of cut blasting and the combined effect of stress waves and detonation gas, the evolution process of wedge cut blasting is divided into two stages, and a theoretical model is proposed to investigate the cavity formation mechanism by theoretical analysis and field tests. In phase one, rock breaking is caused by stress waves. By considering the dynamic strength of the rock, a computational model is built for the rock failure zone derived from the coupled cylindrical charge explosion. In phase two, the driving force of the detonation gas overcomes the total resistance of the surrounding rock mass, accelerates fragments, and then throws fragments to form a cavity. The criterion of cavity formation is established on the basis of the quasi-static loading of the detonation gas. The theoretical model provides an overall interpretation of the cavity formation mechanism, in which stress waves break rock and detonation gas throws fragments. A specific case indicates that the range of the failure zone is approximately 18 times the borehole radius in granite and that the hole-bottom spacing of the wedge cut can be designed as $50 \mathrm{~cm}$; in addition, detonation gas is sufficient to overcome the total resistance, accelerate rock fragments, throw fragments, and form a cavity. Field tests present favourable blasting results, with a high utilization rate of boreholes and uniform fragment sizes. Therefore, the model could provide theoretical support and technical guidance for wedge cut blasting in hard rock.
\end{abstract}

\section{Introduction}

With the rapid progress of modernization, the construction of high-speed railways, freeways, and underground rock projects has grown rapidly. Currently, drilling and blasting methods are still the main methods of tunnel and underground rock space excavation. More than 95\% of mountain tunnels are formed using drilling and blasting in China [1]. Cut blasting is key to creating another free surface for subsequent blasting and influences the overall blasting procedure [2]. Wedge cuts have the advantages of few boreholes, easy rock casting, and low drilling accuracy requirements; thus, these cuts have been widely used in hard rock excavation. Langefors and Kihlstrom [3] studied cut blasting earlier and proposed some cut patterns. Shapiro [4] compared wedge cuts with other cuts and believed that wedge cuts ensured maximum efficiency in soft rock with relatively shallow blast holes, i.e., shallower than $2.5 \mathrm{~m}$. Chakraborty et al. [5] proved that wedge cuts were more productive than parallel cuts in small drivages and developed an empirical relation for the precise prediction of the powder factor and for the specific drilling with wedge cuts by considering rock strength, Barton's rock mass quality, and hole depth. Cardu and Seccatore [6] offered statistics of 
industrial trends in which wedge cuts appeared to be adopted in a wider variety of applications.

Due to the complexity of the mechanism of wedge cut blasting, there are few theoretical studies on the cavity formation of wedge cuts and most of the published literature is about engineering applications. Dai and $\mathrm{Du}$ [7] fully considered the failure modes of different sides of cut rock mass and provided a qualitative explanation for the cavity formation mechanism of wedge cuts, believing that the bottom, left, and right sides had been broken under the action of explosion and that shear failure occurred on the upper and lower sides. Based on the quasi-static theory of detonation gas and the limit equilibrium theory of rock mechanics, Shan et al. [8] analysed the generation process of a cavity by considering that upper, lower, left, and right sides were the result of shear damage and that the underside was due to tensile damage. Furthermore, numerical simulation is used extensively in cut blasting due to its rapid implementation and low cost [9]. Using the dynamic analysis software LS-DYNA, Wang and Konietzdy [10] simulated stress and crack evolution in an infinite rock mass with a single free face during blasting. Yang et al. [11] performed a study of duplex wedge cut blasting with 12 holes via numerical simulation, and the results revealed the propagation of stress waves in hollow cavities and the formation process of cavities at the bottom of the blastholes. Xie et al. [12] adopted the RHT model in LS-DYNA to analyse damage mechanisms of cut blasting under high in-situ stresses and proposed a modified design method applicable to deep rock mass according to numerical optimization simulation. $\mathrm{Hu}$ et al. established a model of wedge cut blasting by combining Auto-CAD with ANSYS and employed LS-DYNA to simulate cavity extension. In terms of temporal and spatial evolution with multidirection cutaway views, the applicability of wedge cut blasting for roadway excavation was studied [13]. Although considerable efforts have been made in past decades to understand the cavity formation mechanism of cut blasting, few studies have considered the whole process of cut blasting from charge initiation to cavity formation. Compared with open-pit blasting, cut blasting is more difficult due to the lack of free surface. The basic process of cut blasting is to break rock, throw fragments, and form a cavity. The hypotheses about cavity formation in wedge cut blasting in the literature are not very reasonable. In addition, the whole process of wedge cut blasting has not been comprehensively considered. Numerical simulation is commonly limited to the research on stress propagation and rock failure, and the consideration about fragments casting is insufficient. Therefore, by considering the characteristics of cut blasting and the effects of stress waves and detonation gas, it is meaningful to investigate the whole process of wedge cut blasting, which includes rock breaking and fragments casting.

Research on postblast fractures suggests that stress waves from the detonating explosive contribute to rock fracturing, while the detonation gas is responsible for moving or throwing fractured rock [14]. Recent studies have revealed that stress waves are responsible for the initiation of the crushed zone and surrounding radial fractures, while the gas pressure further extends the fractures [15]. In this paper, based on the theory of the coaction of stress waves and detonation gas, the evolution process of wedge cut blasting is divided into two stages. In the first stage, assuming that rock breaking caused by stress waves occurs, the objective is to establish a computational model of the rock failure zone by considering the rock dynamic strength. In the second stage, a criterion is proposed for cavity formation based on the quasi-static loading of detonation gas, assuming that the driving force from the detonation gas needs to overcome the total resistance from the reserved surrounding rock mass, accelerate fragments, and then throw fragments to form a cavity. The cavity formation mechanism is investigated via modelling and the theoretical analysis from the initiation of the cylindrical charge to the formation of the cavity.

\section{Failure Zone from Coupled Cylindrical Charge Explosion}

After charge detonation, the rock mass around a borehole is usually divided into three areas based on the failure degree of the rock: the crushed zone, the fractured zone, and the elastic vibration zone. In the near area, the violent explosion shock wave causes a small range of rock crushing, i.e., the crushed zone. Then, the shock wave rapidly attenuates into stress wave, which generates cracks in the middle area, that is, fractured zone I. The stress wave later weakens into seismic wave, which arouses elastic vibration in the far area, known as the elastic vibration zone. Although the detonation gas penetrates into cracks and elongates them, forming fractured zone II, the detonation gas plays a much weaker role in rock fragmentation than the stress waves. In cut blasting, we focus on the crushed zone and fractured zone I caused by the shock wave and the stress wave, respectively, and the combination of these two zones is called the failure zone. The combined effects of explosion shock wave and stress wave are collectively called stress waves in this paper. The partitions of rock blasting around a borehole are shown in Figure 1 [16].

2.1. Blasting Load. After detonation of a coupled cylindrical charge, the blasting impact load directly exerts a force on the hole wall. Because of the lack of feasible measuring methods, empirical formulas are usually adopted to estimate the detonation pressure [17]. Based on the equation of the state of ideal gases, Fickett and Davis [18] and Henrych et al. [19] proposed a simplified formula to calculate the ChapmanJouguet (CJ) detonation pressure from a cylindrical charge:

$$
P_{0}=\frac{1}{1+n} \rho_{0} D^{2}
$$

where $P_{0}$ is the CJ detonation pressure, $\rho_{0}$ is the explosive density, $D$ is the detonation velocity, and $n$ is the specific heat ratio. This equation gives the well-known expression when assuming $n=3$ [20].

The impact load arouses shock wave in the vicinity of the borehole, according to acoustic approximation theory [21]: 


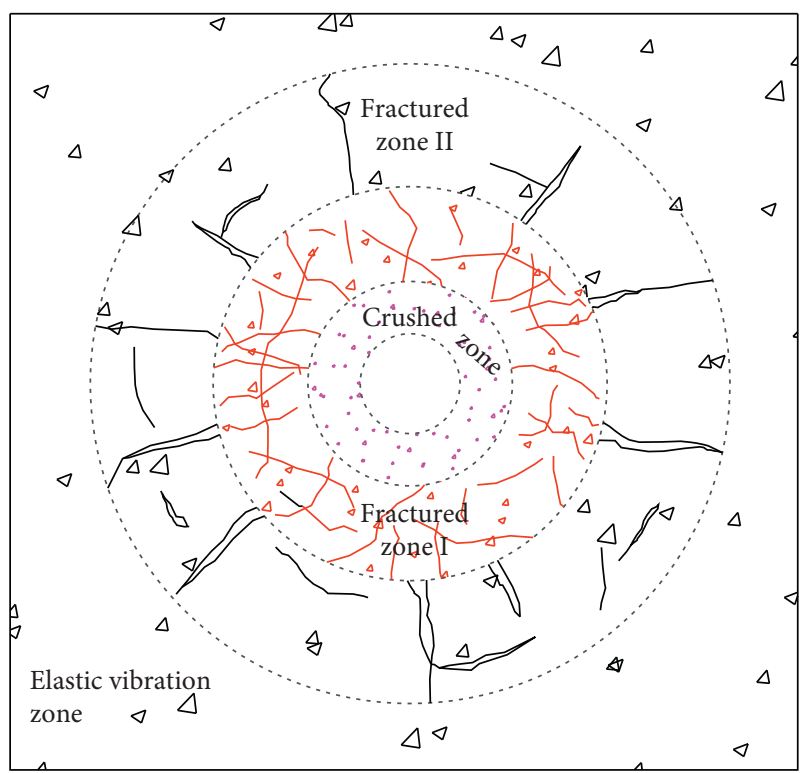

Figure 1: Partitions of rock blasting around a borehole. The combination of the crushed zone and fractured zone I is called the failure zone.

$$
P_{\mathrm{r}}=\frac{2 \rho_{\mathrm{m}} C_{\mathrm{p}}}{\rho_{\mathrm{m}} C_{\mathrm{p}}+\rho_{0} D} \cdot P_{0},
$$

where $P_{\mathrm{r}}$ is the initial pressure of the shock wave on the borehole wall, $C_{P}$ is the longitudinal wave velocity of the rock, and $\rho_{\mathrm{m}}$ is the rock density.

The shock wave causes rock crushing near the charge, which consumes a large amount of energy; thus, the wave rapidly attenuates into stress wave and spreads to the surrounding rock mass, which is subjected to complex stress loading. Since the longitudinal (i.e., axial) dimension of the borehole is significantly larger than the transverse (i.e., radial and circumferential) dimensions and all sections perpendicular to the axis of the borehole are the same, both the radial and circumferential stresses of the rock mass and the constraint conditions hardly change along the axis at the moment of explosion. Thus, this situation can be simplified to a plane strain problem, and the stress at a point in the rock mass can be expressed as

$$
\left\{\begin{array}{l}
\sigma_{r}=P_{\mathrm{r}}\left(\frac{r}{r_{\mathrm{b}}}\right)^{-\alpha}, \\
\sigma_{\theta}=-\gamma \sigma_{r}, \\
\sigma_{z}=\mu_{\mathrm{d}}\left(\sigma_{r}+\sigma_{\theta}\right),
\end{array}\right.
$$

where $\sigma_{r}, \sigma_{\theta}$, and $\sigma_{z}$ are the radial stress, circumferential stress, and axial stress, respectively; $r$ is the distance from the point to the axis of the cylindrical charge; $r_{\mathrm{b}}$ is the borehole radius; $\alpha$ is the coefficient of attenuation, taken as $\alpha_{1}=2+\gamma$ in the shock wave zone and $\alpha_{2}=2-\gamma$ in the stress wave zone; and $\gamma$ is the coefficient of the lateral confining pressure, taken as $\gamma=\mu_{\mathrm{d}} /\left(1-\mu_{\mathrm{d}}\right)$, where $\mu_{\mathrm{d}}$ is the dynamic Poisson's ratio of the rock [21].

The dynamic Poisson's ratio is an important parameter in the numerical analysis of the rock dynamic response. The dynamic Poisson's ratio is related to the load, moisture content, loading rate, and stress state. In some rock engineering applications with limited field data, a value between 0.2 and 0.3 is a common estimate for Poisson's ratio [22]. Generally, the static Poisson's ratio of intact rocks can be directly determined in the laboratory using static tests, and because the dynamic Poisson's ratio is slightly lower than the static Poisson's ratio, the value of the dynamic Poisson's ratio can be estimated by the empirical equation $\mu_{\mathrm{d}}=0.8 \mu$, where $\mu$ is the static Poisson's ratio of the rock $[21,23,24]$.

2.2. Rock Failure Criterion. During blasting, the rock around the borehole is in a state of three-dimensional stress mixed with tension, compression, and shear. This complex stress state of the surrounding rock can be expressed at any point by the equivalent stress [21]:

$$
\sigma_{e}=\frac{1}{\sqrt{2}} \sqrt{\left(\sigma_{r}-\sigma_{\theta}\right)^{2}+\left(\sigma_{\theta}-\sigma_{z}\right)^{2}+\left(\sigma_{z}-\sigma_{r}\right)^{2}} .
$$

When blasting, the rock is subjected to instantaneous impact load. Only when the dynamic strength of the rock is adequately considered can the characteristics of rock blasting be truly reflected. The crushed zone is caused by rock dynamic compression, while fractured zone I is the result of tensile failure. According to the failure characteristics and the von Mises criterion, the rock failure criterion is represented as

$$
\begin{cases}\sigma_{e}>\sigma_{\mathrm{cd}} & \text { (crushed zone), } \\ \sigma_{e}>\sigma_{\mathrm{td}} & \text { (fractured zone } \mathrm{I}),\end{cases}
$$

where $\sigma_{\mathrm{cd}}$ and $\sigma_{\mathrm{td}}$ are the dynamic compressive strength and the dynamic tensile strength of the rock, respectively.

The strain rate effect of rock-like material strength has been generally recognized and accepted by researchers in related fields. According to a study of the strain rate threshold value [25], rock strength presents significant ratedependent characteristics when the strain rate exceeds $5 \times 10^{-4} \mathrm{~s}^{-1}$. The strain rate range of engineering blasting is approximately $10^{0}-10^{3} \mathrm{~s}^{-1}[26]$, and the blasting load belongs to dynamic load with a high strain rate. The dynamic strength of granite increases with the strain rate under a high strain rate, and the rock dynamic strength has a linear relationship with the $1 / 3$ power of the strain rate $[27,28]$, as follows:

$$
\left\{\begin{array}{l}
\sigma_{\mathrm{cd}}=\sigma_{\mathrm{c}} \cdot \dot{\varepsilon}^{1 / 3} \\
\sigma_{\mathrm{td}}=\sigma_{\mathrm{t}} \cdot \dot{\varepsilon}^{1 / 3}
\end{array}\right.
$$

where $\sigma_{\mathrm{c}}$ and $\sigma_{\mathrm{t}}$ are the static compressive strength and static tensile strength of the rock, respectively, and $\dot{\varepsilon}$ is the strain rate, which is higher in the shock wave zone $\left(\dot{\varepsilon}^{1 / 3}=5\right)$ and lower in the stress wave zone $\left(\dot{\varepsilon}^{1 / 3}=3\right)$. 
2.3. Failure Zone of Blasting. The crushed zone generated by shock wave is

$$
\frac{r_{\mathrm{c}}}{r_{\mathrm{b}}}=\left(\frac{K \cdot P_{\mathrm{r}}}{\sqrt{2} \sigma_{\mathrm{cd}}}\right)^{1 / \alpha_{1}},
$$

where $r_{c}$ is the radius of the crushed zone and $K=\sqrt{(1+\gamma)^{2}+2 \mu_{\mathrm{d}}\left(\mu_{\mathrm{d}}-1\right)(1-\gamma)^{2}+\left(1+\gamma^{2}\right)}$.

The fractured zone I is outside the crushed zone, and the interface between these two zones is in a critical state, divided into compression failure and tensile failure. The stress on the interface [21] can be described by

$$
\left\{\begin{array}{l}
\sigma_{r^{\prime}}=\sigma_{r}, \quad r=r_{\mathrm{c}}, \\
\sigma_{e}=\sigma_{\mathrm{cd}},
\end{array}\right.
$$

where $\sigma_{r^{\prime}}$ is the radial stress on the interface between the crushed zone and fractured zone I. Therefore, the fractured zone I resulting from the effect of the stress wave is

$$
\frac{r_{\mathrm{t}}}{r_{\mathrm{b}}}=\left(\frac{\sigma_{\mathrm{cd}}}{\sigma_{\mathrm{td}}}\right)^{1 / \alpha_{2}} \cdot\left(\frac{K \cdot P_{\mathrm{r}}}{\sqrt{2} \sigma_{\mathrm{cd}}}\right)^{1 / \alpha_{1}},
$$

where $r_{\mathrm{t}}$ is the radius of fractured zone $\mathrm{I}$.

The rock failure zone is generated by a coupled cylindrical charge and contains the crushed zone and fractured zone I; thus, it is easy to know that the radius of the failure zone is equal to $r_{\mathrm{t}}$.

\section{Cavity Formation in Cut Blasting}

In phase one, rock is subjected to the dynamic loading induced by stress waves, which typically has a very short duration of a few milliseconds. In phase two, detonation gas penetrates into the broken rock mass, has work done on rock fragments, and throws them. The cavity formation mechanism in wedge cut blasting is investigated by means of a three-dimensional simplified model of the cut rock mass [8].

3.1. Model of Wedge Cut Blasting. A model of wedge cut blasting is shown in Figure 2, where numbers 1-6 represent two rows of inclined boreholes arranged symmetrically; four capital letters constitute a surface, e.g., ACFE represents the free surface and CJNF represents the right lateral side; $L$ is the hole length; $\theta$ is the angle of inclination; $a$ is the hole spacing of the same row; $b$ is the space at the top of symmetrically inclined holes, called hole-top spacing for short; and $c$ is the space at the bottom of symmetrically inclined holes, named hole-bottom spacing for short.

The dynamic loading of stress waves causes rock mass damage in the first stage of cut blasting, and the rock mass is separated into rock fragments of various sizes. Therefore, we treat broken rock as a granular media material that has lost cohesion but reserved internal friction in the subsequent analysis of cavity formation. When detonation gas works in the second stage, it needs to overcome the resistance from the surrounding rock mass, accelerate fragments, and throw fragments to form the cavity. Then, the Mohr-Coulomb strength criterion can be adopted to calculate the shearing resistance on the four lateral sides. A schematic of the

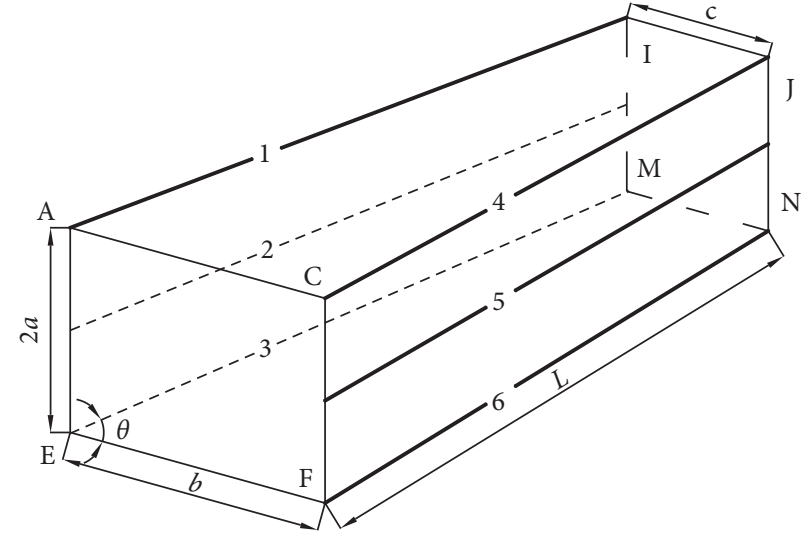

Figure 2: Three-dimensional model of wedge cut blasting.

simplified force analysis for the 3D cut entity is shown in Figure 3. The cut entity is excavated in a semi-infinite geologic body, which is subjected to an in situ stress field of $\sigma_{\mathrm{v}}$ (vertical component) and $\sigma_{\mathrm{h}}$ (horizontal component). The shearing resistance on each of the two lateral sides, AIJC and EMNF, is expressed as $f_{1} ; f_{2}$ expresses the shearing resistance on each of the two lateral sides, AIME and CJNF. $F$ expresses the net force of quasi-static pressure from $k$ inclined boreholes, which is perpendicular to the free surface pointing outwards.

3.2. Cavity Formation Mechanism. According to the Mohr-Coulomb strength criterion, the shearing resistance on each of the two lateral sides, AIJC and EMNF, can be estimated by

$$
f_{1}=\sigma_{\mathrm{v}} \tan \phi \cdot \frac{(b+c) L \sin \theta}{2},
$$

where $\phi$ is the internal friction angle; $\sigma_{\mathrm{v}}$ is the vertical stress, taken as $\sigma_{\mathrm{v}}=\lambda H$, where $\lambda$ is the volume weight of overburden, and $H$ is the buried depth; and $\lambda=\rho_{\mathrm{m}} g$, where $g$ is the gravitational acceleration constant. Similarly, the shearing resistance on each of the two lateral sides, AIME and CJNF, is given by

$$
f_{2}=\sigma_{\mathrm{h}} \tan \phi \cdot\left(\frac{k}{2}-1\right) a L,
$$

where $k$ is the number of boreholes and $\sigma_{\mathrm{h}}$ is the horizontal stress, taken as $\sigma_{\mathrm{h}}=0.72+0.041 \mathrm{H}$ [29].

It should be noted that cohesion appears in neither of these two equations for the calculation of shearing resistance because the broken rock is regarded as a granular media material that has lost cohesion but reserved internal friction.

After the explosion, boreholes are full of detonation gas. According to the quasi-static theory, the force exerted on the rock mass [8] follows the equation

$$
P_{\mathrm{P}}=P_{\mathrm{H}} \cdot 2 r_{\mathrm{b}} L_{\mathrm{c}},
$$

where $P_{\mathrm{P}}$ is the perpendicular force exerted on the lateral side, $P_{\mathrm{H}}$ is the quasi-static pressure, and $L_{\mathrm{c}}$ is the charging length. The theoretical borehole pressure is approximately 


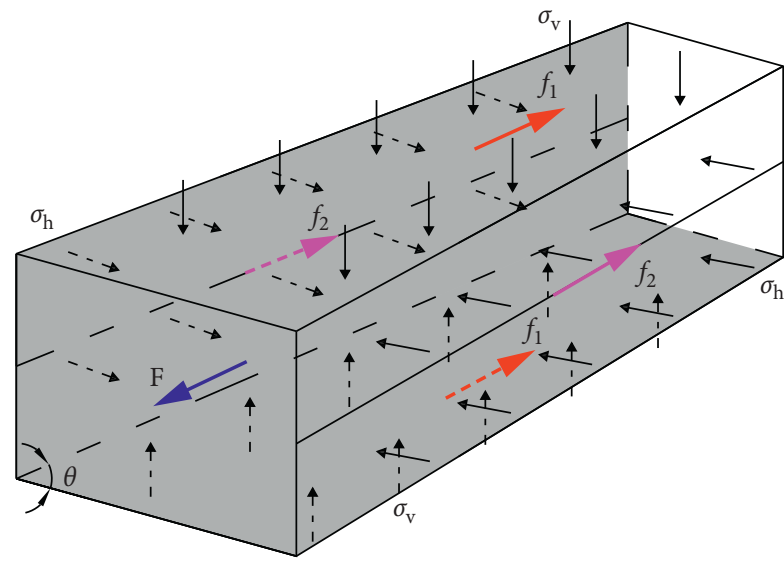

FIgURE 3: Schematic of the force analysis for cut entity.

$45 \%$ of the CJ detonation pressure, assuming complete reaction at the front [17]. According to Persson et al. [20], the borehole pressure with a coupled cylindrical charge can be estimated by $P_{\mathrm{H}}=P_{0} / 2$. The net force from $k$ inclined boreholes perpendicular to the free surface pointing outwards is shown below:

$$
F=k \cdot P_{\mathrm{p}} \cos \theta .
$$

In the second stage of cut blasting, rock casting and cavity formation occur when the loading force of the detonation gas overcomes the total resistance from the reserved surrounding rock mass and accelerates fragments, i.e., subject to the following constraint:

$$
F>2\left(f_{1}+f_{2} \cdot \sin \theta\right) \text {. }
$$

\section{Application to a Project}

4.1. Computational Solution. A large-scale connection tunnel in hard rock, with a buried depth of $230 \mathrm{~m}$, is investigated as an example. The physical and mechanical properties of the rock are listed in Table 1. According to the equations mentioned in Section 2, the crushed zone and fractured zone are obtained in granite caused by No. 2 rock emulsion explosive with $\rho_{0}=1100 \mathrm{~kg} \cdot \mathrm{m}^{-3}$ and $D=3800 \mathrm{~m} \cdot \mathrm{s}^{-1}$. These two zones extend approximately 2.9 times and 18 times the borehole radius; i.e., their scope is approximately 1 to 2.9 times and 2.9 to 18 times the borehole radius, respectively.

The borehole is $45 \mathrm{~mm}$ in diameter; i.e., the borehole radius is $22.5 \mathrm{~mm}$. Therefore, the crushed zone and fractured zone caused by the cylindrical charge explosion extend approximately $r_{\mathrm{c}}=65.3 \mathrm{~mm}$ and $r_{\mathrm{t}}=405 \mathrm{~mm}$, respectively, and the range of the rock failure zone is approximately $405 \mathrm{~mm}$. The hole spacing of the same row is designed on the principle of connecting the failure zones of adjacent boreholes, and the spacing should satisfy the condition $a<2 r_{\mathrm{t}}$, taken as $a=60 \mathrm{~cm}$ here. The determination principle of hole-bottom spacing is usually based on connecting the crushed zones of symmetrical boreholes, and often, the value
TABle 1: Physical and mechanical properties of the rock.

\begin{tabular}{lccccc}
\hline$\rho_{\mathrm{m}}\left(\mathrm{kg} \cdot \mathrm{m}^{-3}\right)$ & $C_{\mathrm{P}}\left(\mathrm{m} \cdot \mathrm{s}^{-1}\right)$ & $\sigma_{\mathrm{c}}(\mathrm{MPa})$ & $\sigma_{\mathrm{t}}(\mathrm{MPa})$ & $\phi\left(^{\circ}\right)$ & $\mu$ \\
\hline 2620 & 5200 & 117.42 & 8.09 & 45.7 & 0.22 \\
\hline
\end{tabular}

is no more than $30 \mathrm{~cm}$. Nevertheless, the hole-bottom spacing is too small to cause the bottom of boreholes to overlap, and rock is excessively crushed in engineering applications. When determining the hole-bottom spacing, it is necessary to ensure that the failure zones connect, i.e., $c<\sqrt{\left(2 r_{\mathrm{t}}\right)^{2}-a^{2}}$, taken as $c=50 \mathrm{~cm}$ here. Figure 4 shows the borehole layout of the wedge cut. The charging length is $200 \mathrm{~cm}$, and the blasting parameters are presented in Table 2 .

When the relevant parameters are substituted into the equations in Section 3.2, the loading force and resistance are derived. The total force on the four lateral sides perpendicular to the free surface pointing inwards is approximately 109.09 MN, which resists rock casting and cavity formation. The net loading force from 8 inclined boreholes perpendicular to the free surface pointing outwards is approximately $488.94 \mathrm{MN}$. Thus, equation (14) is shown to be useable.

4.2. Field Test. Field tests were performed at the Huizhou underground water-sealed oil storage caverns project, which is located in the coastal region of southern China, as shown in Figure 5. There are no active and regional faults near the project site. According to geologic survey, field drilling, and laboratory tests, the strata are mainly composed of mediumfine grained granite with good rock integrity and nondeveloped joint fissures. The physical and mechanical parameters of the granite are shown in Table 1 . The connection tunnel has a width of $12 \mathrm{~m}$, height of $6 \mathrm{~m}$, and length of $150 \mathrm{~m}$, and its cross section has a straight-wall arch profile with an area of approximately $62 \mathrm{~m}^{2}$; the borehole layout and blasting parameters are identical to those introduced in Section 4.1.

Excavation is carried out according to the design. A jumbo driller with three arms is adopted and assisted by manual operation. The cut holes are charged with No. 2 rock emulsion explosive, and a continuous charging structure is used. The blasting parameters are listed in Table 2. Adequate stemming could greatly improve the efficiency of blasting, and a water-soil composite stemming material is used. Figure 6 shows the relevant materials and instruments of the field tests.

Fine mechanical construction guarantees the quality of the field tests, and the task of obtaining a series of statistics has been completed. The utilization rate of boreholes from all twelve field tests is more than $89 \%$, and the average utilization rate is $91.6 \%$, as summarized in Table 3. The advance per round maintains a high level, which is approximately $2.7-2.8 \mathrm{~m}$. The tunnelling face presents a decent flatness after blasting, and the rock has no noticeable outward bulge. Because a detailed fragment size distribution in underground blasting is difficult to obtain, we have chosen three reference values for the fragments to obtain a general 


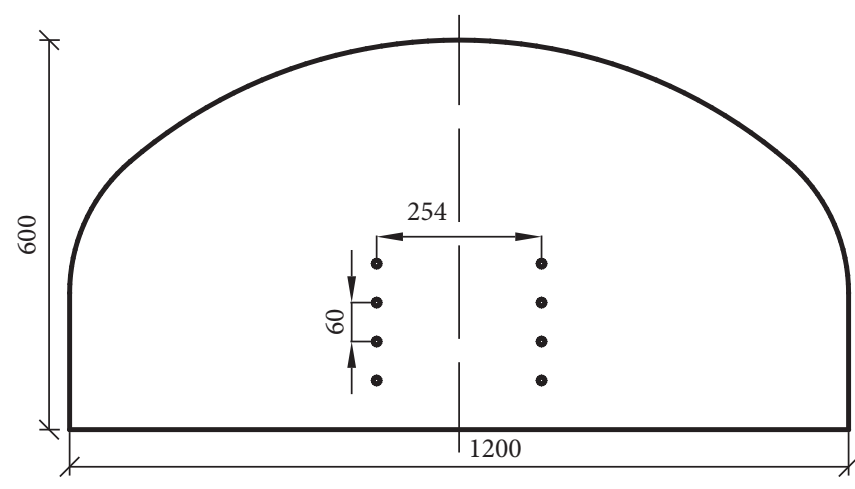

(a)

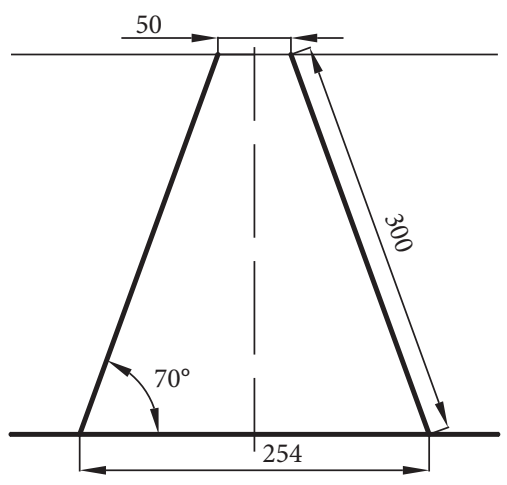

(b)

FIgURE 4: Borehole layout of the wedge cut (unit: $\mathrm{cm}$ ).

TABLE 2: Blasting parameters of the wedge cut.

\begin{tabular}{lcccccccc}
\hline$d(\mathrm{~mm})$ & $L(\mathrm{~cm})$ & $a(\mathrm{~cm})$ & $\theta\left({ }^{\circ}\right)$ & $c(\mathrm{~cm})$ & $L_{\mathrm{c}}(\mathrm{cm})$ & Single charging weight $(\mathrm{kg})$ & Initiation point & Initiation sequence \\
\hline 45 & 300 & 60 & 70 & 50 & 200 & 2.4 & Bottom initiation & Simultaneous \\
\hline
\end{tabular}

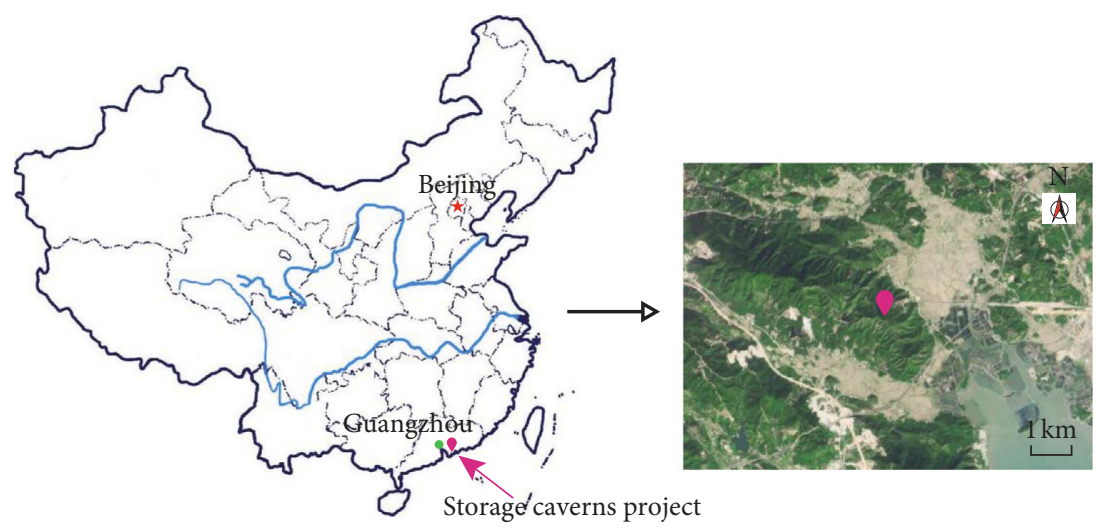

FIGURE 5: Location of Huizhou underground water-sealed oil storage caverns.

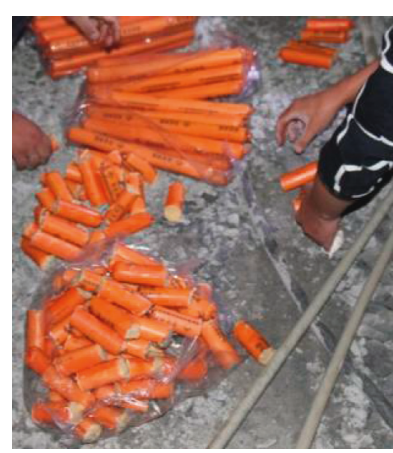

(a)

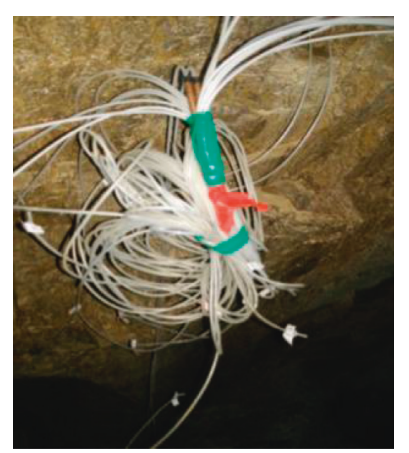

(b)

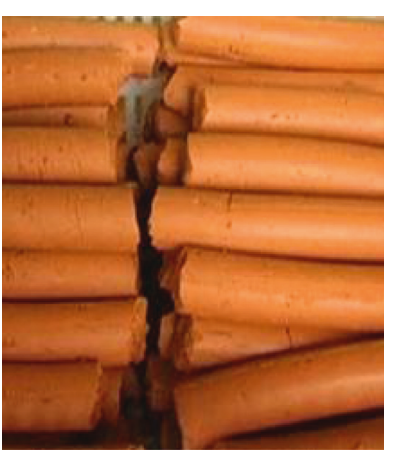

(c)

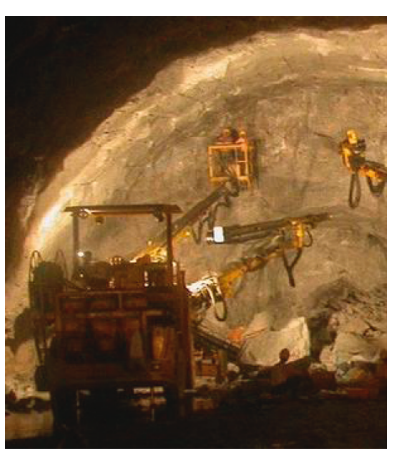

(d)

Figure 6: Relevant materials and instruments of field tests. (a) Explosive. (b) Detonator. (c) Stemming. (d) Driller.

fragment size distribution of the broken rock, as shown in Figure 7. The fragments from 20 to $50 \mathrm{~cm}$ account for approximately $60 \%$ of fragments. The large block ratio is close to $2 \%$, and the largest fragment size is no more than $80 \mathrm{~cm}$. Figure 8 shows some details about the field tests. These results indicate that wedge cut is good for enhancing the advance per round, accelerating excavation, and achieving good blasting performance.

4.3. Discussion. Although the coalescence of stress waves and detonation gas is widely accepted to cause rock fracture and fragmentation during rock blasting, the features of rock 
TABLE 3: Statistics of cut holes.

\begin{tabular}{lcccc}
\hline No. & Hole length $(\mathrm{cm})$ & Advance per round $(\mathrm{cm})$ & Utilization rate of boreholes $(\%)$ & Average value $(\%)$ \\
\hline 1 & 300 & 278 & 92.7 & \\
2 & 300 & 275 & 91.7 & \\
3 & 300 & 273 & 91.0 & \\
4 & 300 & 278 & 89.7 & 91.6 \\
5 & 300 & 267 & 93.3 & \\
6 & 300 & 280 & 91.0 & \\
7 & 300 & 273 & 92.0 & \\
8 & 300 & 276 & 91.7 & \\
9 & 300 & 275 & 91.7 & \\
10 & 300 & 275 & 90.3 & \\
11 & 300 & 277 & 271 & \\
12 & 300 & &
\end{tabular}

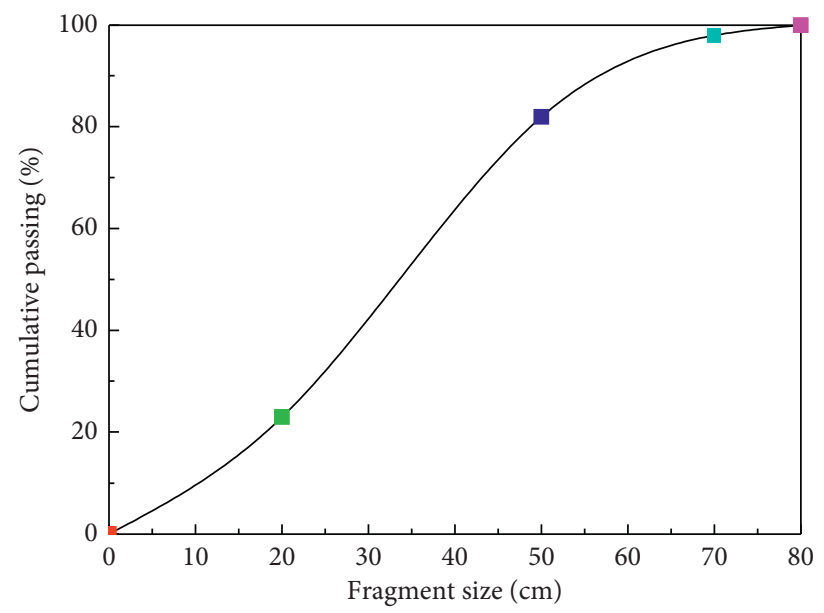

FIGURE 7: Fragment size distribution of the broken rock.

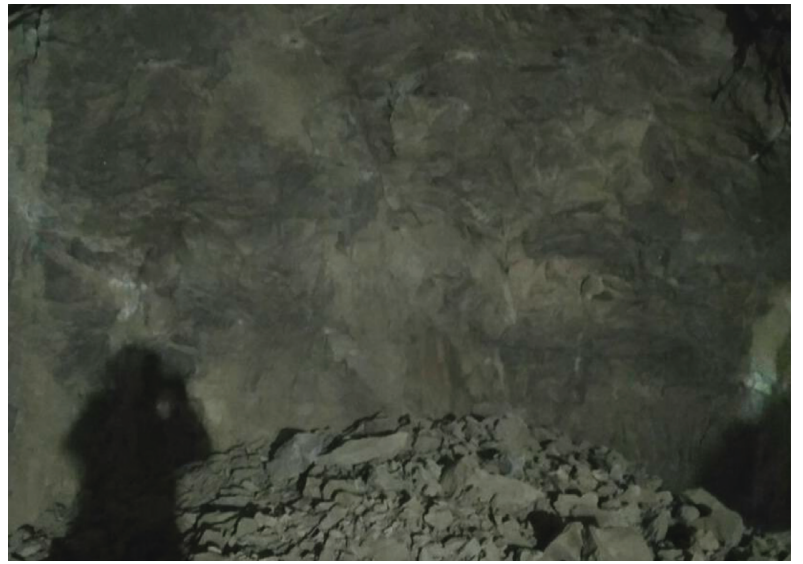

(a)

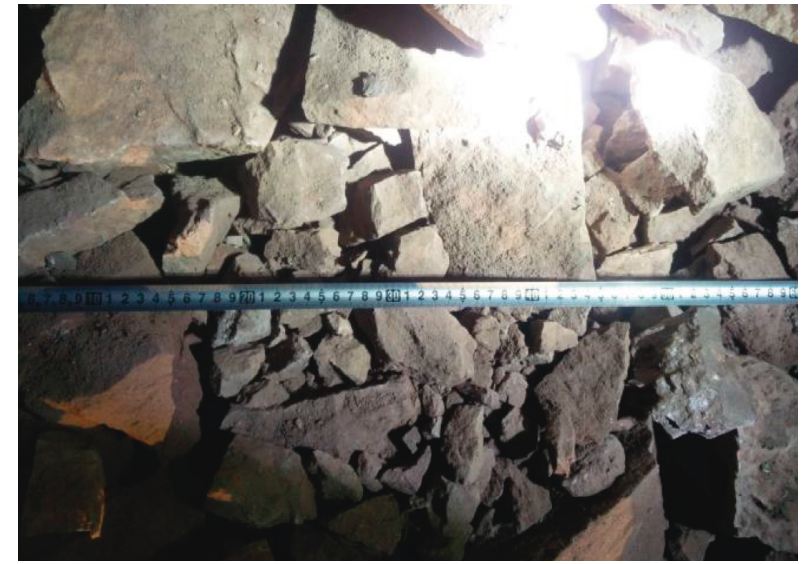

(b)

Figure 8: Details of field tests after blasting. (a) Tunnelling face. (b) Fragments.

breaking still vary considerably because of significant differences in the physical and mechanical properties and structural characteristics of engineering rock mass. Stress wave loading plays a dominant role in rock fracturing and is key to rock crushing and initial crack formation. Related numerical results showed that a model that considers only stress waves could make reasonable predictions of the rock mass response to blasting load [15, 30-35]. The effect of rock fragmentation caused by stress waves is more obvious in hard rock.

The crushed zone and the fractured zone appear around the borehole when a coupled charge explosion occurs in an 
infinite rock, and the scopes of these two zones are approximately 3-7 times and 8-150 times the borehole radius, respectively [36]. Many models have been proposed to estimate the scope of the zones around a borehole. Hustrulid suggested that the $r_{\mathrm{c}} / r_{\mathrm{b}}$ did not exceed 3-5, and Esen et al. indicated that the range of $r_{\mathrm{c}} / r_{\mathrm{b}}$ was between 1.3 and 6.6 [17]. According to Чанукаев, the crushed zone was approximately 2-3 times the charging radius and the fractured zone was approximately 10-15 times. Dai suggested that the crushed zone and the fractured zone were approximately 1.6-2.7 times and 13-17 times the charging radius, respectively, and these two zones caused by No. 2 rock emulsion explosive in granite were approximately 3.7 times and 24 times, respectively [21]. Tang et al. suggested that the crushed zone and the fractured zone were approximately 2.5-6.0 times and 16-26 times the charging radius, respectively, and these two zones caused by TNT explosive in granite were approximately 1.7 times and 12.9 times, respectively [37]. In this paper, the crushed zone and the fractured zone caused by No. 2 rock emulsion explosive in granite are approximately 2.9 times and 18 times the borehole radius, respectively; that is, the scope of the two zones is approximately 1-2.9 times and 2.9-18 times the borehole radius, respectively. Although the crushed zone and the fractured zone derived from the proposed model are only considered stress waves, these two zones are consistent with the results from the models in the literature. Although this choice may cause the calculations of the failure zone to be slightly low, the impact is very small. Thus, it has been verified that the proposed model shows good applicability for predicting failure zones. The model could predict the blast-induced failure zone caused by the coupled cylindrical charge well in wedge cut blasting. In addition, this model provides theoretical support to determine cut parameters, such as hole spacing and hole-bottom spacing.

The hole-bottom spacing is taken as $50 \mathrm{~cm}$, which is larger than conventional values. As spacing increases, more energy is used to generate and extend cracks; thus, a wider fractured zone can be acquired rather than a wider crushed zone. The increase helps avoid borehole overlap during drilling and excessive rock crushing in blasting. With a larger spacing, the number of boreholes decreases for the same cross section, which saves time and reduces resource consumption. Therefore, although the value of hole-bottom spacing is larger than conventional values, we could achieve better blasting results and greater efficiency.

Some previous studies indicate that detonation gas does not contribute significantly to fracture propagation and is responsible for moving or throwing rock fragments $[14,36,38]$. In the second stage of blasting, detonation gas penetrates into the broken rock mass, swells, and has work done on fragments. The quasi-static force of detonation gas is as high as $489 \mathrm{MN}$, while the resistance is approximately $109 \mathrm{MN}$. Therefore, this force can sufficiently overcome the resistance from the reserved surrounding rock mass, and fragment casting occurs after fragments speed up. Then, a cavity forms that provides another free surface and rock swelling space for subsequent blasting. However, if the detonation gas is strong enough that excess energy remains after overcoming the resistance, the gas may have too much work done on the fragments, leading to a higher velocity, farther casting distance and more difficult mucking. Past investigations on the cavity formation mechanism of cut blasting frequently paid more attention to the propagation law of stress waves, while neglecting fragments casting and cavity formation. In this paper, when analysing the formation of a cavity, the broken rock mass is regarded as granular media that have lost cohesion but reserved internal friction under the impact of stress waves. The formation mechanism of the cavity is reasonably explained from a mechanical perspective of detonation gas.

The average utilization rate of boreholes from twelve field tests is as high as $91.6 \%$, and the volume of the cut cavity is approximately $6.5 \mathrm{~m}^{3}$. Thus, the specific charge is approximately $2.9 \mathrm{~kg} \cdot \mathrm{m}^{-3}$, which means that slightly more explosives are consumed. The rock is well fragmented, with uniform fragment sizes and hardly any large blocks, and the cavity is well formed. These results mean that the rock mass has been broken previously because of stress wave loading before the detonation gas throws fragments to form the cavity. Field tests have verified the feasibility of the cut design based on rock breaking and fragment casting caused by stress waves and detonation gas, respectively, and the blasting results indicate the validity of modelling and analysing the cavity formation mechanism of wedge cut blasting.

\section{Conclusions}

In this paper, by considering the characteristics of cut blasting and the combined effects of stress waves and detonation gas, a theoretical model of the whole process from charge initiation to cavity formation is proposed and then applied to engineering practice. The conclusions can be summarized as follows:

(1) Dynamic loading from stress waves plays a dominant role in rock breaking. The scope of the rock failure zone caused by the coupled cylindrical charge in granite is approximately equal to 18 times the borehole radius according to theoretical calculation. The hole-bottom spacing of the wedge cut can be designed as $50 \mathrm{~cm}$, which is significantly larger than the conventional value.

(2) Detonation gas is responsible for rock fragment casting. When the driving force from quasi-static pressure overcomes the total resistance from the reserved surrounding rock mass and accelerates fragments, fragment casting occurs, leading to cavity formation.

(3) Considering the coalescence of stress waves and detonation gas together during rock blasting, the evolution process of wedge cut blasting has been divided into two stages, which contains the compression damage and the tensile damage caused by stress waves and the fragment casting caused by detonation gas. For wedge cut blasting, the theoretical model makes an overall interpretation of the mechanism. 
This study is based only on theoretical analysis and a specific case, and more blasting tests are needed to provide theoretical support and technical guidance for wedge cut blasting in hard rock.

\section{Data Availability}

The data used to support the findings of this study are included within the article.

\section{Conflicts of Interest}

The authors declare that there are no conflicts of interest.

\section{Acknowledgments}

This research was financially supported by the National Natural Science Foundation of China (Nos. 51674062 and 51474049), the National Science Foundation for Young Scientists of China (No. 51604061), and the Basic Scientific Research Operating Expenses of Central University (No. N160104009). We wish to thank Guangdong People Blasting Engineering Co. Ltd. and The First Engineering Co. Ltd. of CTCE Group for supporting the field tests and assisting with data collection. Special thanks are due to American Journal Experts for its professional English editing service.

\section{References}

[1] W.-B. Lu, Y. Luo, M. Chen, and D.-Q. Shu, "An introduction to Chinese safety regulations for blasting vibration," Environmental Earth Sciences, vol. 67, no. 7, pp. 1951-1959, 2012.

[2] Z. Zhao, Y. Zhang, and H. Bao, "Tunnel blasting simulations by the discontinuous deformation analysis," International Journal of Computational Methods, vol. 8, no. 2, pp. 277-292, 2011.

[3] U. Langefors and B. Kihlstrom, Modern Technology of Rock Blasting, Metallurgical Industry Press, Beijing, China, 1983.

[4] V. Y. Shapiro, "Efficiency of cut configuration in driving tunnels with a set of deep blast holes," Soviet Mining Science, vol. 25, no. 4, pp. 379-386, 1989.

[5] A. K. Chakraborty, P. Pal Roy, J. L. Jethwa, and R. N. Gupta, "Blast performance in small tunnels-a critical evaluation in underground metal mines," Tunnelling and Underground Space Technology, vol. 13, no. 3, pp. 331-339, 1998.

[6] M. Cardu and J. Seccatore, "Quantifying the difficulty of tunnelling by drilling and blasting," Tunnelling and Underground Space Technology, vol. 60, pp. 178-182, 2016.

[7] J. Dai and X. Du, "Research on blasting parameters of wedgeshaped cutting for rock tunnel driving," Mining Research and Development, vol. 31, no. 2, pp. 224-232, 2011.

[8] R. Shan, B. Huang, W. Gao, Y. Zhu, and X. Hao, "Case studies of new technology application of quasi-parallel cut blasting in rock roadway drivage," Chinese Journal of Rock Mechanics and Engineering, vol. 30, no. 2, pp. 224-232, 2011.

[9] T. Bernard and P. Dozolme, "The digital simulation of blasts: a major challenge for mines in the 21st century," Procedia Engineering, vol. 83, pp. 100-110, 2014.

[10] Z. L. Wang and H. Konietzky, "Modelling of blast-induced fractures in jointed rock masses," Engineering Fracture Mechanics, vol. 76, no. 12, pp. 1945-1955, 2009.

[11] G. L. Yang, L. L. Jiang, and R. S. Yang, "Investigation of cut blasting with duplex wedge deep holes," Journal of China
University of Mining \& Technology, vol. 42, no. 5, pp. 755-760, 2013.

[12] L. X. Xie, W. B. Lu, Q. B. Zhang, Q. H. Jiang, M. Chen, and J. Zhao, "Analysis of damage mechanisms and optimization of cut blasting design under high in-situ stresses," Tunnelling and Underground Space Technology, vol. 66, pp. 19-33, 2017.

[13] J. Hu, C. Yang, K. Zhou, B. Zhou, and S. Zhang, "Temporalspatial evolution and application of blasting cavity of single wedge cutting," Journal of Central South University, vol. 48, no. 12, pp. 3309-3315, 2017.

[14] S. Nie and M. Olsson, "Study of facture mechanism by measuring pressure history in blast holes and crack lengths in rock," in Proceedings of the Twenty-Seventh Annual Conference on Explosives and Blasting Technique, Orlando, FL, USA, January 2001.

[15] O. Yilmaz and T. Unlu, “Three dimensional numerical rock damage analysis under blasting load," Tunnelling and Underground Space Technology, vol. 38, no. 9, pp. 266-278, 2013.

[16] Z. Leng, W. Lu, M. Chen, P. Yan, and Y. Hu, "A new theory of rock-explosive matching based on the reasonable control of crushed zone," Engineering, vol. 12, no. 6, pp. 32-38, 2014.

[17] S. Esen, I. Onederra, and H. A. Bilgin, "Modelling the size of the crushed zone around a blasthole," International Journal of Rock Mechanics and Mining Sciences, vol. 40, no. 4, pp. 485-495, 2003.

[18] W. Fickett and W. C. Davis, Detonation, University of California Press, Berkeley, CA, USA, 1979.

[19] J. Henrych, R. Major, and Č. A. Věd, The Dynamics of Explosion and Its Use, Academia, San Francisco, CA, USA, 1979.

[20] P.-A. Persson, R. Holmberg, and J. Lee, Rock blasting and explosives engineering, CRC Press, Boca Raton, FL, USA, 1993.

[21] J. Dai, "Calculation of radii of the broken and cracked areas in rock by a long charge explosion," Journal of Liaoning Technical University (Natural Science), vol. 20, no. 2, pp. 144-147, 2001.

[22] H. Gercek, "Poisson's ratio values for rocks," International Journal of Rock Mechanics and Mining Sciences, vol. 44, no. 1, pp. 1-13, 2007.

[23] P. Segarra, J. A. Sanchidrián, R. Castedo, and I. del Castillo, "Coupling of blasting seismographs to rock and its effectiveness for horizontal ground motion," International Journal of Rock Mechanics and Mining Sciences, vol. 92, pp. 81-90, 2017.

[24] C. Liu, J. Yang, and B. Yu, "Rock-breaking mechanism and experimental analysis of confined blasting of borehole surrounding rock," International Journal of Mining Science and Technology, vol. 27, no. 5, pp. 795-801, 2017.

[25] C. Liang, X. Li, S. Li, J. He, and C. Ma, "Study of strain threshold value between static loading and quasi-dynamic loading of rock," Chinese Journal of Rock Mechanics and Engineering, vol. 31, no. 6, pp. 1156-1161, 2012.

[26] M. Cai, P. K. Kaiser, F. Suorineni, and K. Su, "A study on the dynamic behavior of the Meuse/Haute-Marne argillite," Physics and Chemistry of the Earth, Parts $A / B / C$, vol. 32, no. 8-14, pp. 907-916, 2007.

[27] F. Gong, D. Lu, X. Li, and Q. Rao, "Experimental research of sandstone dynamic strength criterion under different strain rates," Rock and Soil Mechanics, vol. 34, no. 9, pp. 2433-2441, 2013.

[28] S. Kubota, Y. Ogata, Y. Wada, G. Simangunsong, H. Shimada, and K. Matsui, "Estimation of dynamic tensile strength of sandstone," International Journal of Rock Mechanics and Mining Sciences, vol. 45, no. 3, pp. 397-406, 2008. 
[29] W. Zhao, Rock Mechanics, Central South University Press, Changsha, Hunan, China, 2010.

[30] F. Donze, J. Bouchez, and S. Magnier, "Modeling fractures in rock blasting," International Journal of Rock Mechanics and Mining Sciences, vol. 34, no. 8, pp. 1153-1163, 1997.

[31] G. W. Ma, H. Hao, and Y. X. Zhou, "Modeling of wave propagation induced by underground explosion," Computers and Geotechnics, vol. 22, no. 3-4, pp. 283-303, 1998.

[32] H. Hao, C. Wu, and Y. Zhou, "Numerical analysis of blastinduced stress waves in a rock mass with anisotropic continuum damage models part 1: equivalent material property approach," Rock Mechanics and Rock Engineering, vol. 35, no. 2, pp. 79-94, 2002.

[33] S. H. Cho and K. Kaneko, "Influence of the applied pressure waveform on the dynamic fracture processes in rock," International Journal of Rock Mechanics and Mining Sciences, vol. 41, no. 5, pp. 771-784, 2004.

[34] G. W. Ma and X. M. An, "Numerical simulation of blastinginduced rock fractures," International Journal of Rock Mechanics and Mining Sciences, vol. 45, no. 6, pp. 966-975, 2008.

[35] J.-H. Shin, H.-G. Moon, and S.-E. Chae, "Effect of blastinduced vibration on existing tunnels in soft rocks," Tunnelling and Underground Space Technology, vol. 26, no. 1, pp. 51-61, 2011.

[36] S. Huang, L. Luan, W. Xing, and Q. Liu, "Instantaneous rock blasting wave and its microscopic characteristics during interaction with concrete," Shock and Vibration, vol. 2015, Article ID 318286, 6 pages, 2015.

[37] T. Tang, J. Zhou, H. Wu, Y. Xu, and J. Ma, "Theoretical calculation of breakage zones caused by cylindrical charge blasting," Blasting, vol. 31, no. 3, pp. 23-27, 2014.

[38] L. Liu and P. D. Katsabanis, "Development of a continuum damage model for blasting analysis," International Journal of Rock Mechanics and Mining Sciences, vol. 34, no. 2, pp. 217-231, 1997. 


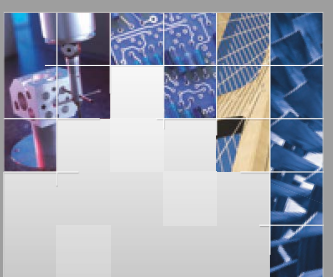

\section{Enfincering}
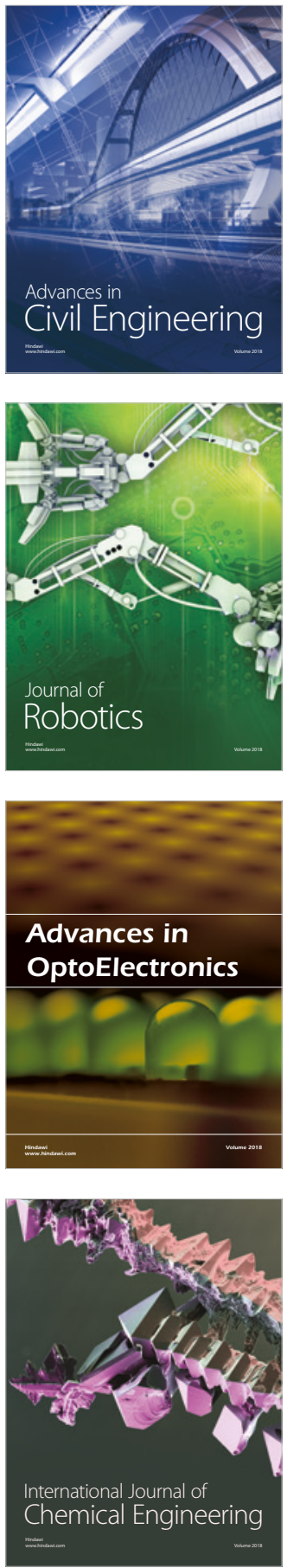

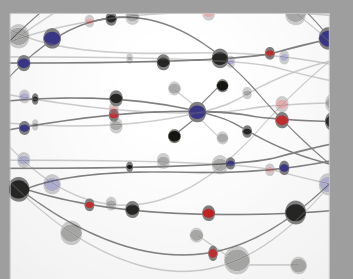

\section{Rotating \\ Machinery}

The Scientific World Journal

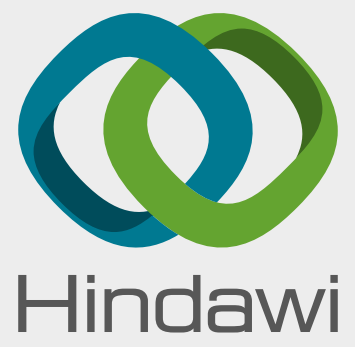

Submit your manuscripts at

www.hindawi.com
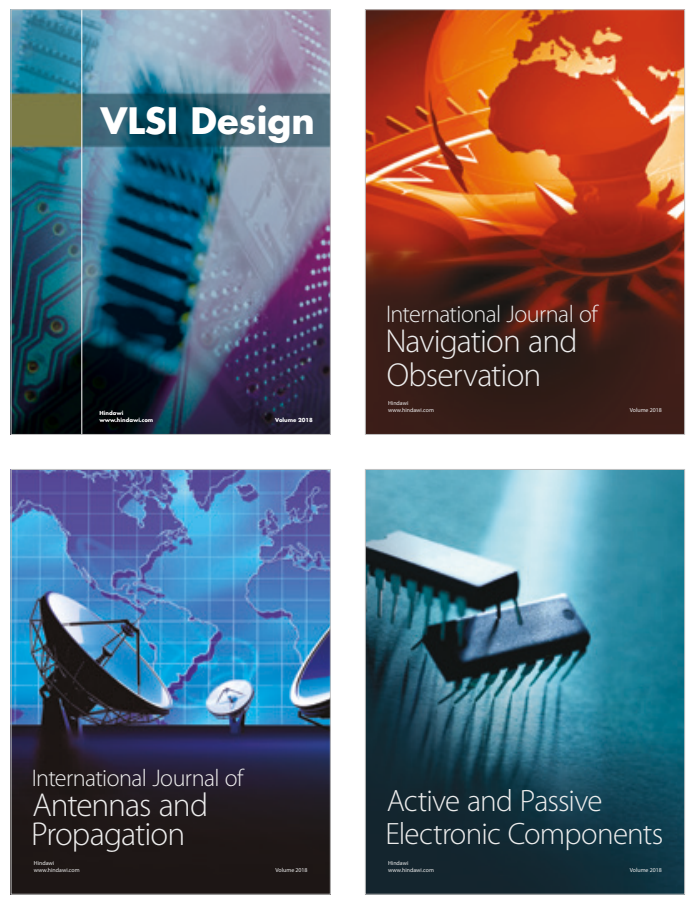
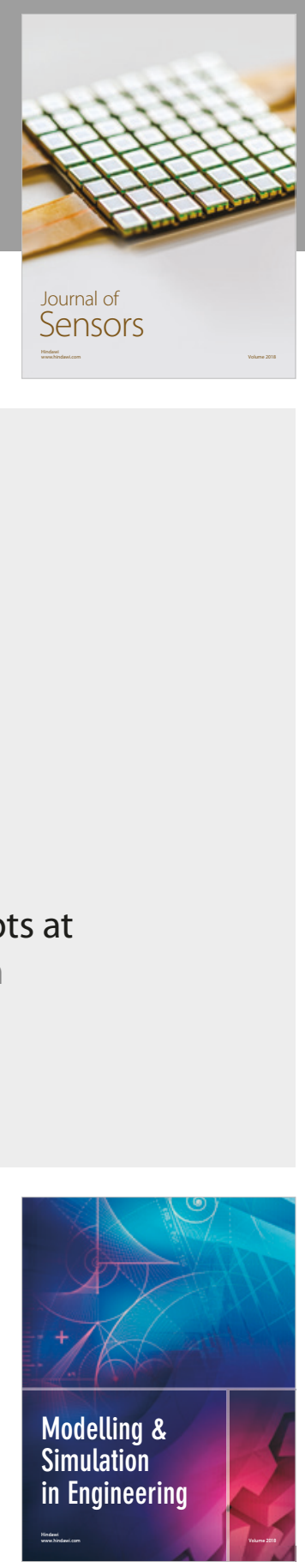

\section{Advances \\ Multimedia}
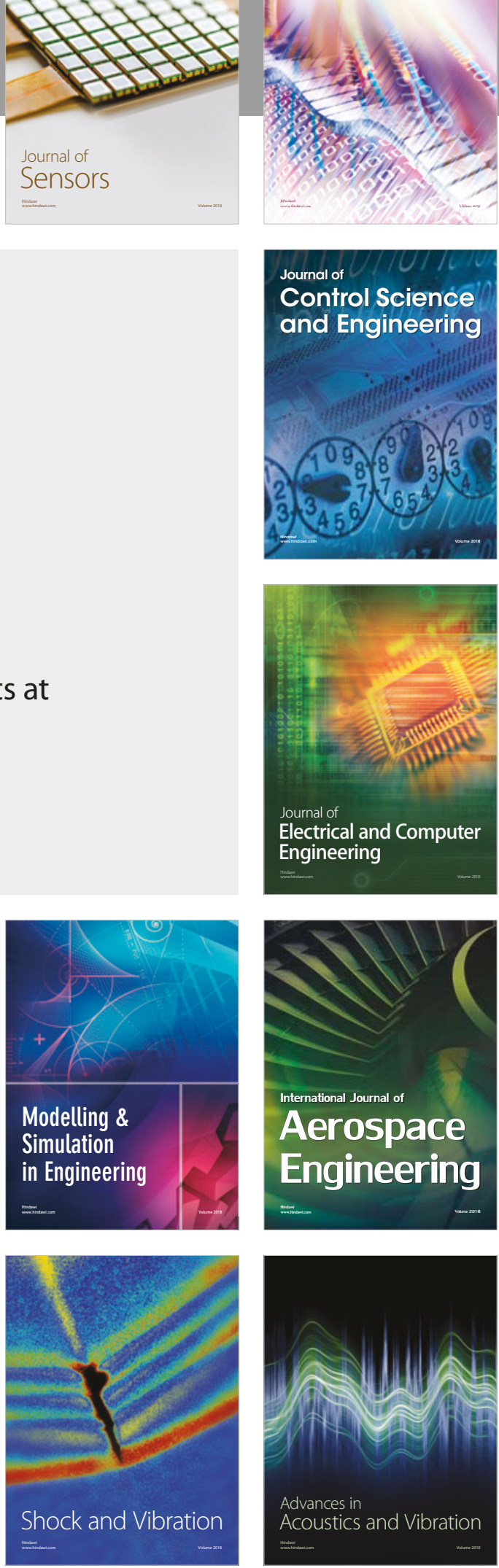